\title{
Facility Mapping of University of Lagos
}

\author{
Esther Oluwafunmilayo Makinde, Seyi Adewale Adebangbe, \\ Babajide Abdulahmeen Erinjogunola
}

Department of Surveying and Geoinformatics, Faculty of Engineering, University of Lagos, Lagos, Nigeria

Email: estherdanisi@gmail.com, seyibangbe@gmail.com, ericbabajide@gmail.com

How to cite this paper: Makinde, E.O., Adebangbe, S.A. and Erinjogunola, B.A. (2017) Facility Mapping of University of Lagos. Journal of Geoscience and Environment Protection, 5, 166-180. https://doi.org/10.4236/gep.2017.512012

Received: September 15, 2017

Accepted: December 25, 2017

Published: December 28, 2017

Copyright @ 2017 by authors and Scientific Research Publishing Inc. This work is licensed under the Creative Commons Attribution International License (CC BY 4.0).

http://creativecommons.org/licenses/by/4.0/

\begin{abstract}
This paper shows a detailed methodology for creating 2D and 3D visual facility map of the campus. The purpose of this study work is to develop an interactive interface containing the 2 and 3-Dimensional features of all the facilities within the University of Lagos. The spatial attributes of the facilities were collected with the aid of total stations. The most recent Google earth software was used as source of data to produce 2-dimensional facilities of the study area through digitization process. SRTM Digital elevation model image was downloaded from United State Geological Survey website to give the elevation data required for the 3-dimensional representation. All these data were processed with ArcGIS 10.2.1.
\end{abstract}

\section{Keywords}

GIS, Digital Elevation Model (DEM), 2D Map, 3D Map

\section{Introduction}

Facilities are designed and created to serve a particular purpose in a convenient way. Catering facilities are created for catering services in a more hygienic and speedy way, toilet facilities are created to provide toilet services, educational facilities provide a good learning services, etc. Facility mapping is however the process of identifying the spatial locations of these facilities in relation to one another and to see at a glance their interactions. The process would help in improvement of space planning and general operational management.

The major importance of FM application development is to provide a decision support system for the decision makers that will make utilities more efficient and effective. The components of the application varies with respect to the demand of the users. The components have become dynamic with the adoption of GIS in the mapping.

FM application may be grouped into the following general categories: query 
and display; design/work order processing; equipment maintenance; network analysis and customer service/service call analysis. Two examples, query and display, and design/work order processing, should serve to illustrate the range of FM systems [1]. Using GIS to integrate geographic with other corporate data has become absolute to this task, (ESRI).

\section{Statement of Problem}

The purpose behind the concept of facility mapping is to develop an improved way of matching the demand and supply subject to set objectives and constraints. Due to the increasing demand for better and easier systems, facility mapping requires frequent data and systems update. For the GIS created for utilities to be complete, there must be the availability of digital base-maps. These base-maps are basically lacking in our country. The experiences with GIS implementation in utilities in Nigeria reveal that each institution is now creating digital base-maps just for its own use. This creates unnecessary duplication of maps of varying scales and accuracy [2], so there is need to create not just a base-map but an accurate up-to-date automated/interactive facility map of the campus, because map should be interactive and dynamic since facilities are being added almost every day and everyone in the community should have access to this facilities on the go i.e. the locations of these facilities and the services they render.

\section{Aim and Objectives of the Work}

The aim of this study work is to develop an android based system with interactive interface containing the 2- and 3-dimensional features of all the facilities within the University of Lagos. The system will afford users the ability to be able to view and see the services of these facilities at a go and on the go. The system is also to ensure that future update or changes can easily be effected.

The objectives are to:

1) Identify the locations, detailing the description of access to any facilities of interest within the study area;

2) Acquire and populate the attributes of all the facilities within the study area;

3) Produce a 2-dimensional map of the spatial distribution of these facilities;

4) Produce a 3-dimensional visualization map of the study area.

\section{Significance of the Study}

The outcome of this project work would serve as data for engineering and construction purposes, this project presents a system to assist stakeholders, students and the general community in identifying where facilities are located. This model will also serves as a basis for future planning of the university.

\section{Literature Review}

Several organizations have been managing a number of assets in their facility 
portfolio using GIS for several years. In recent years, GIS has been applied in electricity distribution in an equitable and efficient manner, pavement management at airports and in utility management. In [3], he discussed GIS applications adoption by US Air force to provide decision support system for the handlers of the Air Force bases management affairs.

Aerial Imagery or Global Positioning Systems (GPS) are the most commonly used primary sources of spatial data to be used for a facility geodatabase. While the aerial imagery give a bird eye view of the nature of the facilities and through which the physical attributes of the facility can be derived from, the GPS fixed the relative position of the facility to the centre of the earth surface. The limitations of these two data sources are often the fact that they could not penetrate the roof to see through what is inside a covered facility. This limitation led to increasing demand for more improved technologies to reduce the significant holes that this has left in the creation of facility geodatabases.

New technologies such as Computer Aided Design (CAD) floor plains or Building Information Model (BIM) are bridging the gap from the aerial imagery and GPS. The new technology provides inside information about the facilities to give a more complete description of the facilities. The integration of the new technology and geo-technology is making it gradually possible to unmask the business activities taking place inside the building [3].

Today, GIS provides a good alternative to analyze the spatial aspects of components of facility management workflows in a cost effective manner. It provides support system that will optimise use of financial and human resources leading to optimal productivity.

However, according to [3], he said that no much achievement has been recorded in developing multidimensional visualization model that will provide a business support system. Such system will incorporate element of space, time and money in business decision making processes support systems. This system if developed will provide an advanced spatial analytic support system to support businesses that are situated in multiple geographical areas.

GIS provides platform that support the integration of information from spatial, temporal and informational dimensions. Such integrations provide solutions such as:

1) Optimal use of resources by integrating cost data with the visualization of space and occupancy.

2) Routing path for immediate evacuation during emergency.

3) Determining the total value of the land and property assets which the city has sold within a particular period of time.

4) Shortest route to deliver sold to the homes of new customers.

5) Model to determine and predict the spread and direction, effect of fire at any particular weather condition.

6) Visualization of energy consumption data at the room level while simultaneously managing maintenance workflows for mechanical, electrical and 
plumbing systems for a nationwide facility infrastructure

Surface data such as topographical surfaces, aerial photos, parcel delineation. Paved and unpaved roads, wetlands, agricultural lands, soils map, building footprints, water bodies, CAD designs showing information not provided by aerial imagery can all be integrated using GIS to produce a base map of the area. The map could serve as a campus tour guide for the students and visitors. This map will assist in identification and collection of information about any features within the area. At Troy University, ArcGIS was used to generate the 3-D model of campus.

GIS tool provide efficient and effective management of surface and subsurface facilities. Subsurface facilities however create a daunting challenge to the managers, information such as exact location, network distribution and analysis, and management of sub surface facilities, are extremely tasking to the managers. Adoption of GIS has simplified the problems associated with the management of these subsurface facilities. This can be identified by integration of aerial photo or any other ground feature with underground facilities, and then perform measurements; such as geographical location and the area extent. Also, GIS can provide network-based spatial analysis for utilities including flow direction and topology creation. Moreover, GIS can be used to track work orders such as landscape and utilities maintenance. For example, a list of maintenance tasks showing the description and location in the work order.

In landscape management, GIS mapping and display capabilities can be used to map out the landscape features such as flowers, trees and other plants and them displayed using the symbols embedded in ArcMap. The locations of these features will be collected using GPS and plotted for display in ArcMap. These features have symbols in ArcMap that depict them. These features can further be draped on the digital elevation model to give a more accurate surface model of the landscape. ArcMap has graphical representation for different kind of trees and the ability to include schedule for regular requirements of watering, pruning, weeding, and fertilizing. Thus, GIS can help in maintenance of landscape appearance and increases productivity of the facilities department staff [4].

GIS can be used in facility space planning such as emergency planning and response. In space planning, map can contain the parking spaces allocated for visitors and students, accessible buildings, routes, etc. These can further being reclassified into handicap parking space, buildings that are handicap accessible. Ferries State University (FSU) in its adoption of GIS to provision of services for physical challenged students, it integrates aerial photographs with other mapping techniques to map out handicap accessibility facilities. The space planning was possible by delineating the suitable areas in ArcMap using the aerial photograph as the data source. Pedestrian and Transportation planning can also be carried out showing paths on campus such as different paths for bicycles, cars, motorcycles while also displaying visitors and students parking spaces. This can be colour coded to differentiate one path from the other or one parking space 
from another.

Parking, Transit and Traffic services (PTTS) at Texas A \& M University uses the campus GIS for mapping and managing bus routes, striping work on streets and parking lots, keeping track of signs, and managing parking lot allocations. PTTS is planning, with the Police Department, to implement a dispatching system for bus, police and 911 emergency uses [5].

In emergency planning and response management, GIS can be used to show fire hydrants and display their locations. In the event of a fire or earthquake, a campus planner will be able to determine the area that are prone to fire risk and the area that are risk free. During the fire outbreak, GIS would be able to provide risk free path through which people can be evacuated from. In addition, it helps a campus planner under any emergency to quickly locate water and gas shut-off valves [4].

Generation of 3D maps and events requires careful planning and design processes. The first process will be to examine the design process which will influence the look of the final outcome. The examination of the process is to have a better understanding of the application of the cues and resources to give a required output. The first step of the design process is data modelling. This involved data analysis, format conversion, etc. At this stage, geometric and semantic aspects are reshaped and aggregated and classified in the format required with the specific software used for designing and producing 3D maps.

Symbolization is the next step. This step involves defining the legend for both the Digital terrain model section and the thematic objects. The last step is visualization. Parameters are chosen for creating the image and completing the scenery that will become the final 3D map [6].

\section{Graphic Aspects of 3D Map}

There are important cues that influence the map creation process. Taken together these cues are known as "graphic aspects" (or "design aspects"). The different kinds of maps and map creation steps require many graphic aspects to be distinguished by cartographers [6].

Graphic aspects ensure that it is possible to design and control all map features, including how features should appear in the perspective view. Every graphic aspect includes one or more graphic variables. Similar to the design process of 3D maps, all graphic aspects need to be divided into similar groups. There are three graphic objects required in the creation process. The graphic objects are:

1) DTM objects: This dataset describes the earth's surface numerically by a huge amount of terrain points.

2) Topographic objects may be classic vector objects, external $3 D$ objects, or mostly raster objects, such as textures. Not only single objects, but also object groups with a specific characteristic in their appearance and, perhaps, behaviour. They are the result of aggregation within the modelling process. 
3) Orientating objects are already defined features that assist the map user with extracting geo-information from the map. They complete the model of a 3D map (Haeberling C., 2002). For example, co-ordinate lines or labelling objects are absolutely necessary to express the accurate geo-positioning and the notations of map objects [6].

Regarding the geometric shape of objects, the user has some possibilities to determine the original outlines of the objects in different manners. Simplification of the shape can be accomplished by eliminating vertices or creating polylines instead of curves, or by determining the object's shape for later application of a level-of detail mechanism. Positioning concerns include whether the object will obey its geo-referenced position or its referenced position in relation to neighbouring objects. Thematic objects need to be adjusted to facilitate harmonious data classifications. The semantics of objects is yet another consideration in the modelling process. Changing thematic attributes or spatio-temporal dependencies, typically done in an attributes table, connects all objects to the appropriate database [6].

\section{Study Area}

The area under study is the University of Lagos, Akoka Campus located on the western part of Lagos metropolis in Yaba Local Government Area of Lagos State. The University is geographically located between Northings $721000 \mathrm{~N}$ and $718500 \mathrm{~N}$, and Easting $542000 \mathrm{E}$ and $545000 \mathrm{E}$ and has an approximate area of $3.25 \mathrm{Km}^{2}$ (325 Hectares). On the western and south-western borders are located Iwaya and Akoka communities respectively. On the North and North-western flank, the University is bordered by Bariga (Shomolu Local Government Area), a canal which is non-navigable because of debris that is found in it is located along the western flank stretching northwards and southwards while the famous Lagos Lagoon borders the eastern part of the campus which, unlike the canal, is a navigable waterway.

\section{Methodology}

This contains methods and procedures followed in data acquisition, processing and manipulation of data obtained from the field and also from secondary sources in order to achieve the aim of the research. The field work was carried out between in December of 2017. Total Station was used to get the X, Y and Z data for the surface of the study area while Remote Elevation Measurement (REM) was used to get the height of buildings for the 3D modelling with the aid of Reflector-less Total Station. The field data was downloaded from the Total station and copied to a notepad and then opened in Microsoft Excel environment. The excel file was opened in ArcMap using display X, Y data tool and subsequently converted to shapefile format. The shapefile was added as layer. The layer was overlaid on the Google Earth image of the study area, there was a little shift, which was corrected using spatial adjustment tool in ArcGIS. 


\section{Field Data Rectification}

Spatial adjustment tool of ArcGIS was used in rectifying the points.

Rectification method: A new shapefile was created in the ArcCatalog.The fields of the new shapefile (point) must have the same fields with the shapefile of the points gotten from the field, digitized out the exact points the points were gotten from on the field, Use the attribute transfer tool to drag the old points on the new ones. Automatically the new points will carry the properties of the old points.

\section{Validation through KML (Keyhole Mark-Up Language)}

The rectified points were converted to KML file using the conversion tool in ArcGIS and exported to Google earth for validation.

\section{Validation through Topology Building}

New personal geodatabase was created in ArcCatalog inside the project working folder. Feature datasets were created in the geodatabase while multiple feature classes digitized from the google earth were imported into the created featured datasets. For topology validation, the Topology wizard in ArcCatalog was used to select and include all participating feature classes in validation process and the topology rules were added. The validation errors were fixed using the topology fix error tool. Finally the features were converted to KML using the Conversion tool in the ArcTool box, and they were all exported to Google earth for final validation. The screen shot of the validated features is shown in Figure 1.

\section{Facility Map Production}

Google earth imagery was downloaded from Google earth using Google

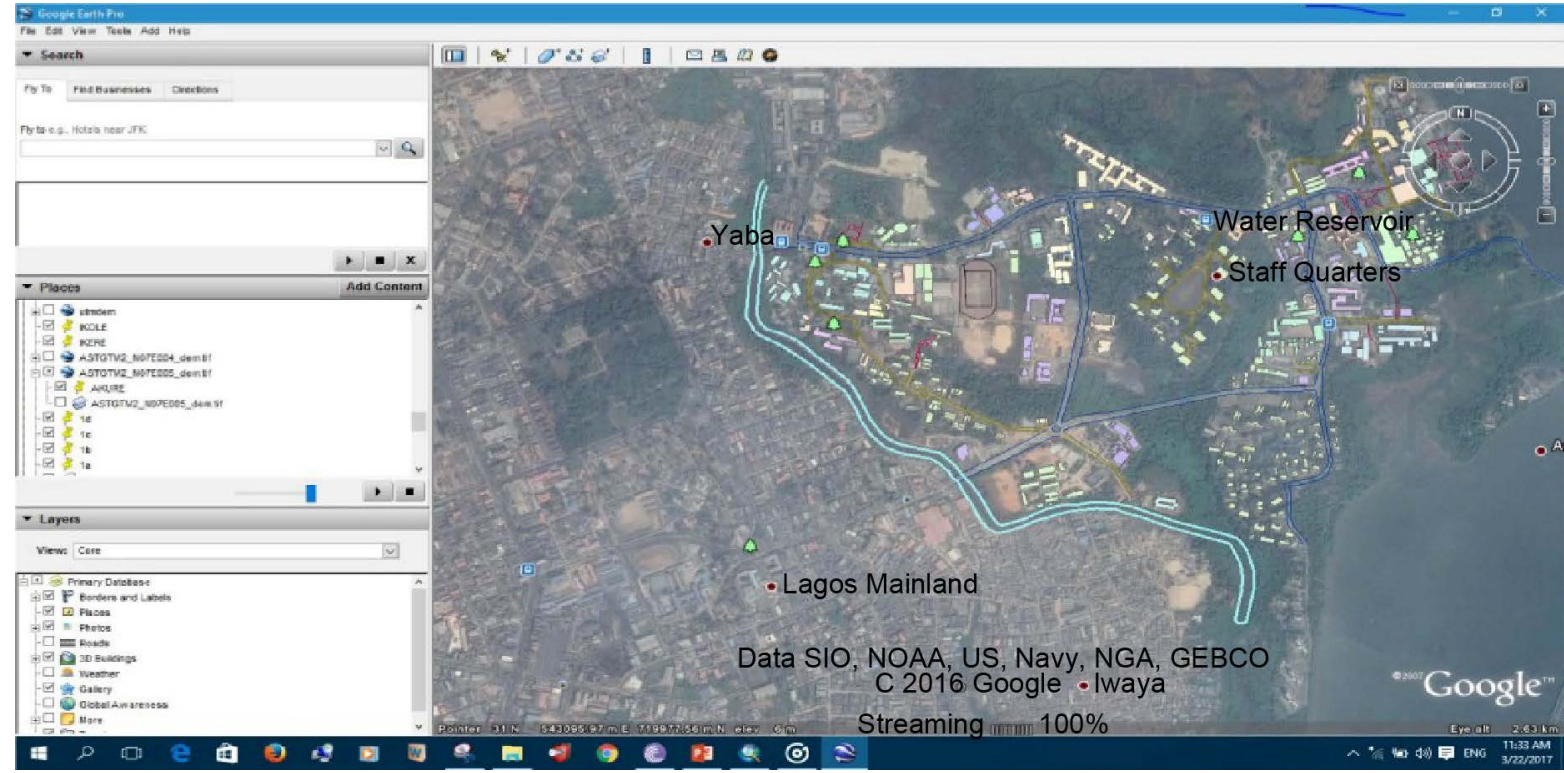

Figure 1. Showing validated features. 
downloader. The buildings were digitized from the downloaded Google earth image using ArcGIS 10.2.1. Shapefiles for the facilities were created in ArcCatalogue. The created shapefiles were added to ArcMap and editor was started to digitize out to facilities. The road network, buildings are extracted using polyline and polygon respectively while street lights and trees are represented by point data for 3D map production the generated 2D map is shown in Figure 2, Figure 3 shows the old 2D CAD map of the campus.

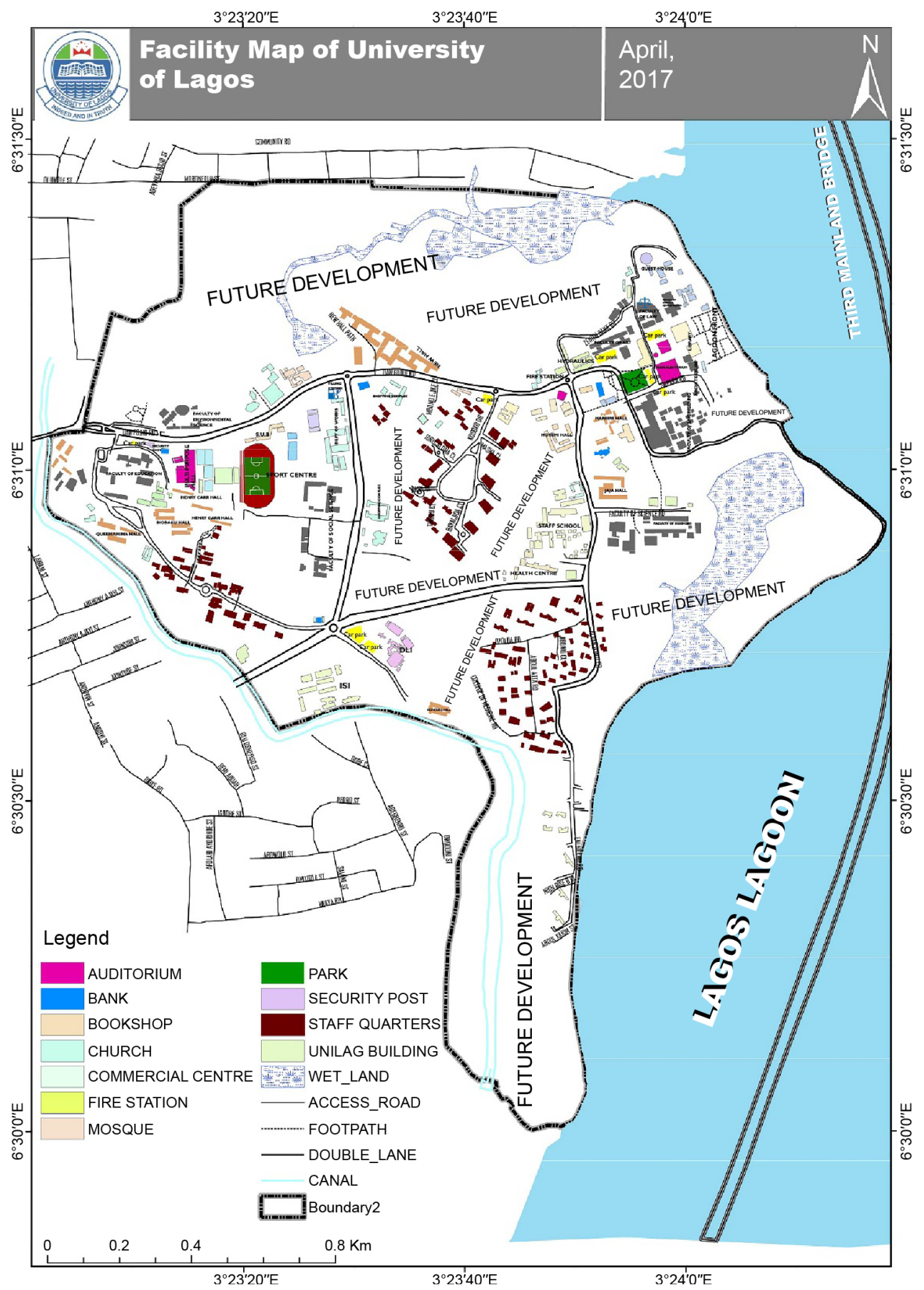

Figure 2. Showing the 2D facility map of the study area. 


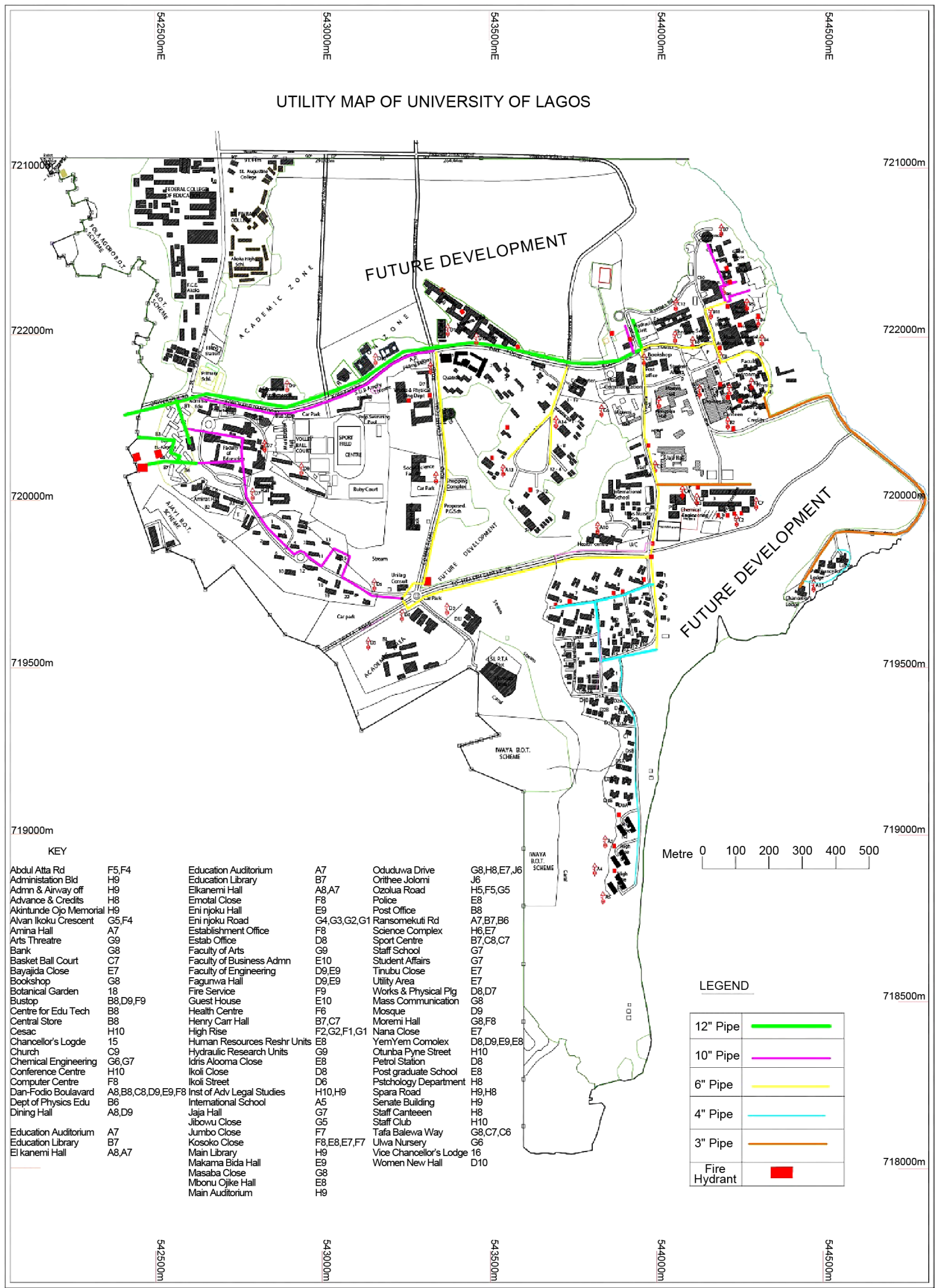

Figure 3. Showing the old 2D map of the study area. 


\section{Topographical Map (DEM)}

The $\mathrm{X}, \mathrm{Y}$ and $\mathrm{Z}$ data gotten from the field were added to ArcMap. Kriging interpolation technique was used to create the Digital Elevation Model (DEM). SRTM DEM was also downloaded from USGS website and was clipped with the study area using clip tool of ArcGIS ArcTool box

The two DEM images were called up in ArcScene of ArcGIS 10.2.1 and were extruded from the property to give it a $3 \mathrm{D}$ look.

\section{3D Map Production}

The 3D image was done ArcScene using the created DEM, The created DEM was added to ArcScene and extruded with the heights gotten on the field. Extrusion incorporates the height of these features in their representation to give them $3 \mathrm{D}$ look and were made to float on DEM to have a true land representation.

The created DEM was also added to ArcScene, The height of the buildings gotten from the field were added to the already created height field in the attribute table of each of the facility shapefile in ArcMap. ArcScene was launched and all the shapefiles were added, from the table of content each shapefile was right clicked on to access the property dialog box, from the property dialog box the shapefiles were extruded to give them $3 \mathrm{D}$ look and were made to float on the DEM to have a full $3 \mathrm{D}$ visualization.

\section{Findings}

This study has demonstrated a capability of GIS in facility mapping with different visualizations techniques i.e. $2 \mathrm{D}$ and $3 \mathrm{D}$ visualization, Figure 2 shows the generated 2D map while Figure 4(a) and Figure 4(b) show cross-sections of the generated 3D map of the campus. All the facilities were geo-located with the aid of total station and imported into ArcGIS 10.2, the facilities were also digitized from the Google earth image downloaded for the study area. 3D topographic maps of the study areas were created from the point data gotten from field-work and also from the downloaded SRTM DEM image downloaded from USGS, Figure 5 shows the 2D Topographic map generated from the point data gotten from the field using Total station while Figure 6 shows the 3D topographic map generated using the same data source. Figure 7 shows the $2 \mathrm{D}$ topographic map generated from SRTM 30 m while Figure 8 shows the 3D topographic map generated using the same data source. The $2 \mathrm{D}$ facility map was produced by digitizing all the facilities out as features from the Google earth image downloaded using Google downloader. The 3D model of the campus was produced by exporting all the features created in ArcMap to ArcScene for extrusion, the extruded features were made to float on the 3D topography map created through interpolation using Kriging method. The $3 \mathrm{D}$ visualization gives the study area a near real life view.

\section{Discussion}

Although Department of works and Physical Planning has the 2D facility map 


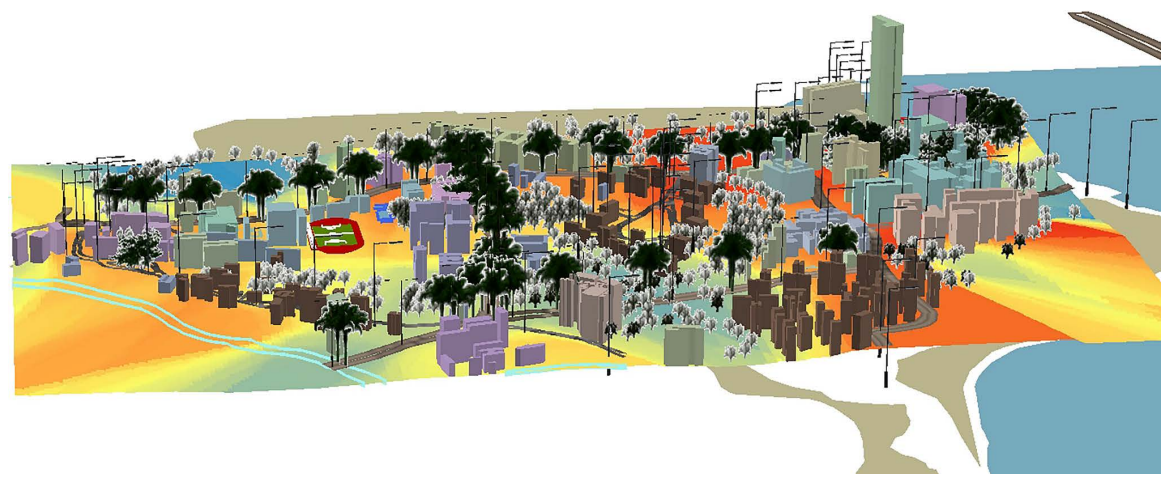

(a)

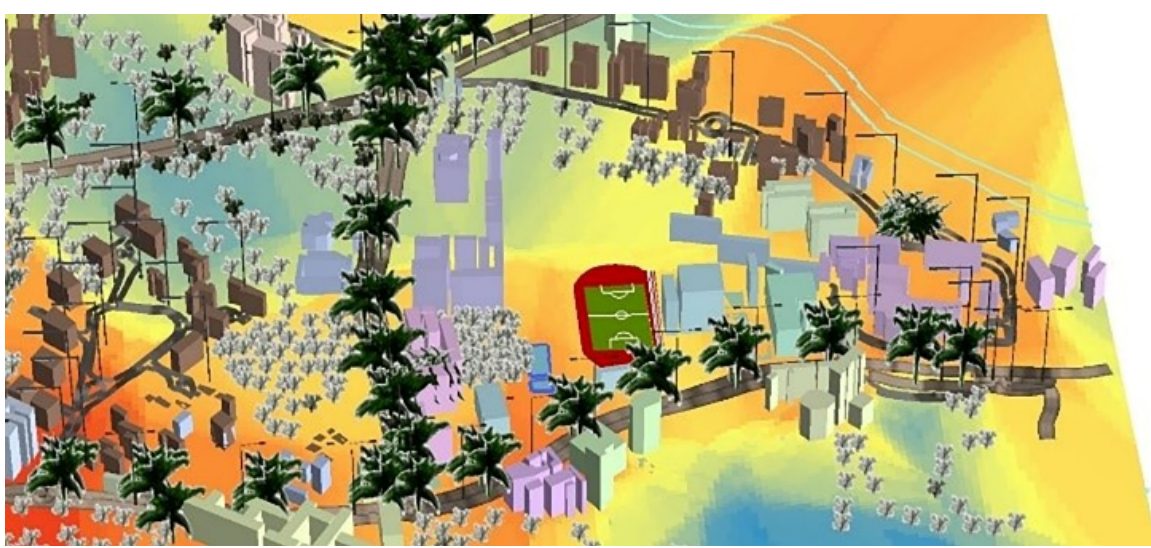

(b)

Figure 4. (a) Showing a cross-section of the 3D model of the study area; (b) Showing a cross-section of the 3D model of the study area.

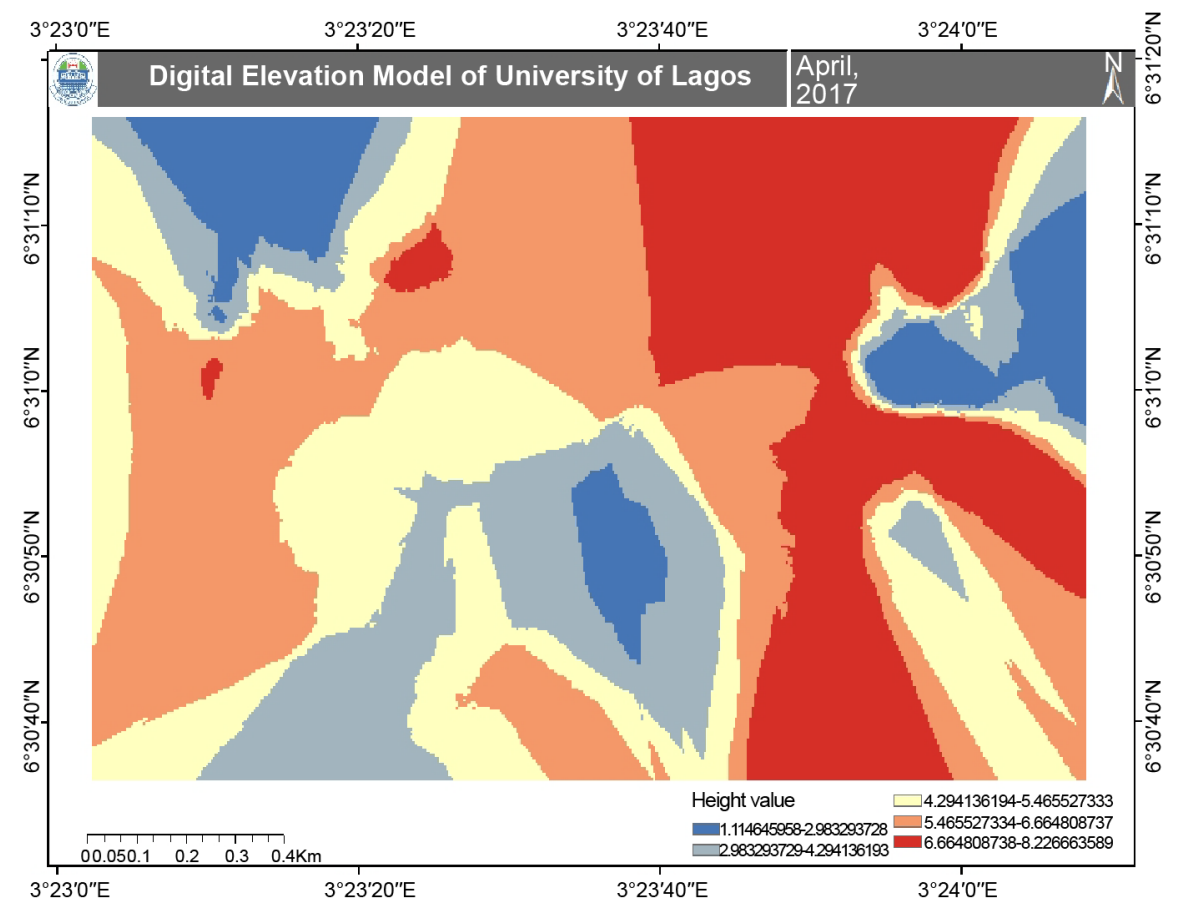

Figure 5. Showing the 2D DEM (Digital elevation model) of the study area (derived from the field data). 


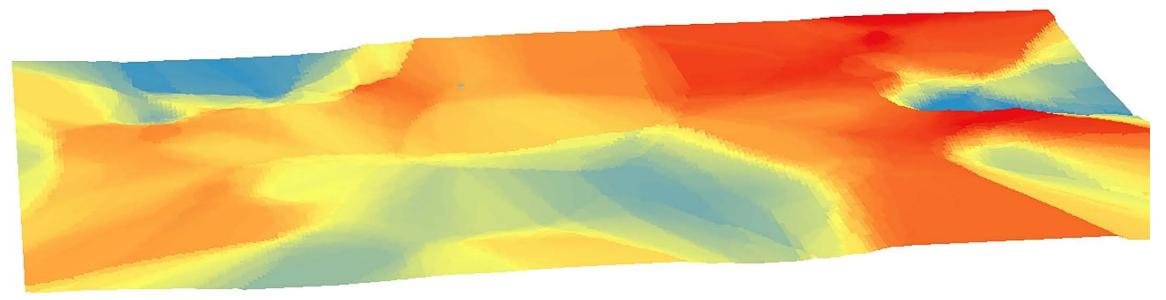

Figure 6. Showing 3D DEM (Digital Elevation Model) of the study area (derived from the field data).

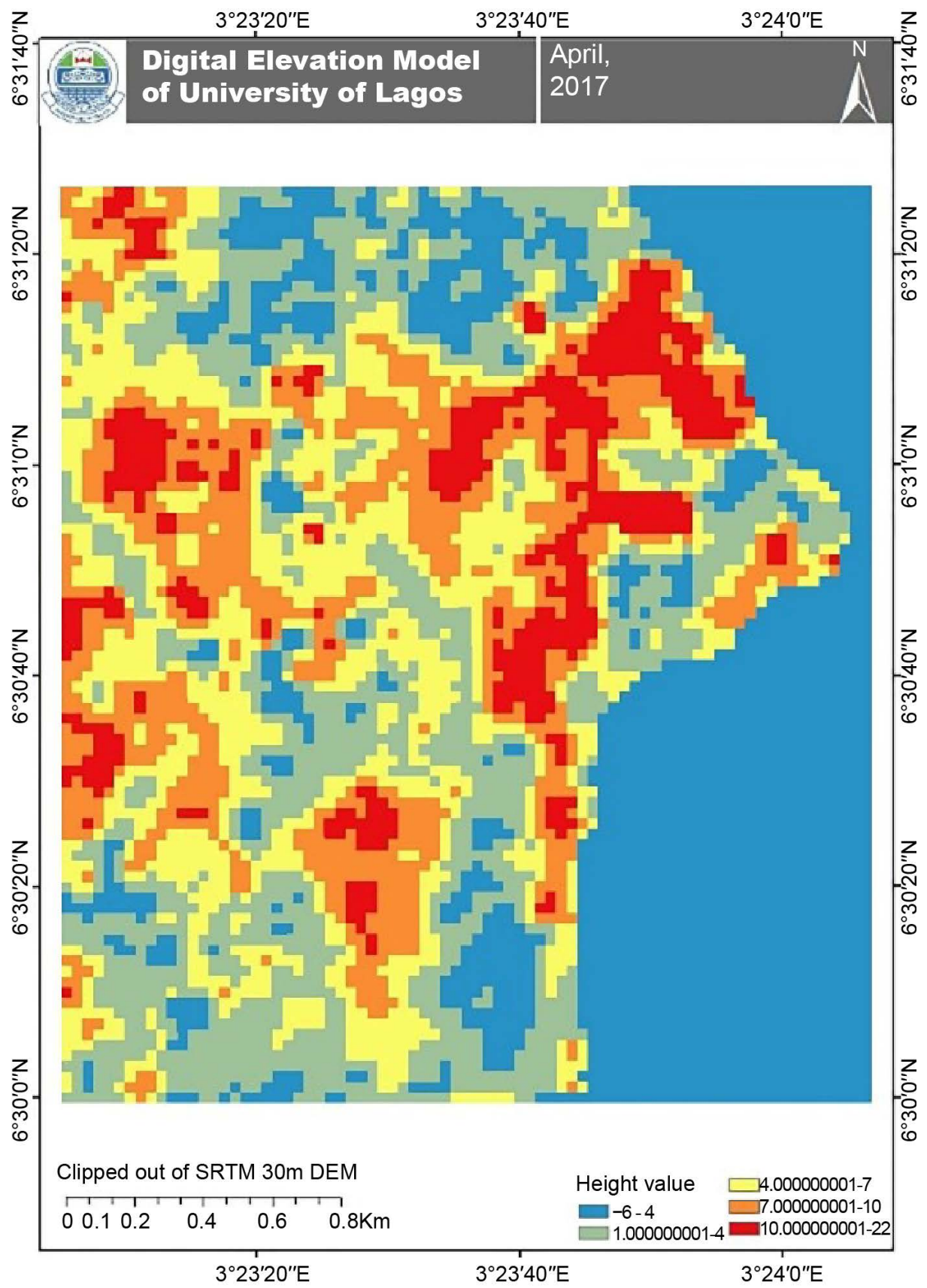

Figure 7. Showing the showing the 2D DEM (Digital Elevation Model) of the study area (derived from SRTM 30 m DEM). 


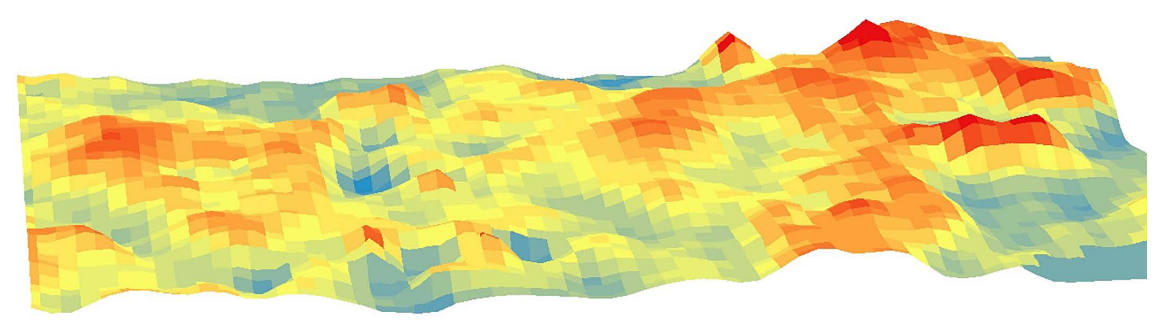

Figure 8. Showing 3D DEM (Digital Elevation Model) of the study area (derived from SRTM 30 m DEM).

(Figure 2) readily available but there is need for an updated version, hence the reason for producing a 2D facility map of the study area. The already available facility map only gives a simple $2 \mathrm{D}$ visualization and analysis of the university features, this study went from 2D to $3 \mathrm{D}$ spatial model which provides the $3 \mathrm{Di}$ mensional model of an area for an interactive and simplified view and study, which is better for easy and better decision making.

[7] modelled 3D of UNIBEN educational Land-use from Shuttle Radar Topographic Mission (SRTM) Digital Elevation Model (DEM) data draped on GeoEye satellite image to give a 3D impression using ArcScene 10.1 Software. The height of each building was extruded from digitized footprint. From the 2D and 3D image maps produced, a campus navigation simulation and animation was geovisualized, although this study also modelled the topography of the study area from SRTM [Figure 8], we also went a step further to also model it using the point data collected from our field work, which gives room for comparison and at the end we chose the 3D topographic modelled (Figure 6) from the field work because it looks more realistic and accurate, the 2D features extracted from Google Earth image was draped on the 3D topography created and extruded using the height value of the buildings gotten from the field work. ArcScene 10.2 software was used, finally Bello E. used assumed building heights but we used height gotten from the field using Robotic Reflector-less Total Station to get the heights.

[8] used The NigeriaSat-1 and Ortho-rectified Quick-Bird images, land-use master plan and topographic map were used to generate datasets for facilities mapping and management of Abuja Federal Capital City, Phase 1. The following datasets were derived: digital road network, DTM, Tourism map, Urban and Cadastral development maps, and many more for the National Geospatial Data Infrastructure, although we extracted the facilities features from satellite image too, we relied more on the data collected from the field as a means of ground-truthing the digitized features but more importantly to generate the study area $3 \mathrm{D}$ topography.

To rectify the point data collected from the field spatial adjustment tool (attribute transfer) was used, [9] in his work "The Accuracy of GIS Tools for Transforming Assumed Total Station Surveys to Real World Coordinates" used the transformation tools built in ArcGIS (e.g. spatial adjustment tool and geore- 
ferencing tool), to transform un-projected total station precise observations into projected real world coordinates these tools use affine transformation. An affine transformation is any transformation that preserves collinearity (i.e., all points lying on a line initially still lie on a line after transformation) and ratios of distances. In general, an affine transformation is a composition of rotations, translations, dilations (scales), and shears (skews). The transformation functions are based on the comparison of the coordinates of source and destination points, also called control points [10]. In their work "Development of a Blunder Detection Approach for Automated Point Matching during Vector to Image Data Integration" also used weighted affine transformation to filter point matches during automated integration of vector roads with images. The transformation is applied to a local area of match points to detect probable blunders and remove them from the rubber-sheeting algorithm.

To validate the study geodataset, we used [7] methodology "3D Cartographic Model And Animation of As-built Educational Land-use of UNIBEN, Nigeria" he validated positional accuracy validation of UNIBEN facility map using Google Earth viewer, the KML (Keyhole Mark-up Language) converted geovisualized data fell in their appropriate locations on Google Earth, thus validating reliability and the positional accuracy of the modeled 3D dataset for further use, for this project the same thing was done (Figure 1), but we went a step further to validate the geometric accuracy of the shapefiles, topology rules in ArcGIS was used to modeled the shapefile relationship accurately.

The 2D and 3D model carried out in this project identified numerous cultural and natural ground features, which include the following: Culture: roads, buildings, power transmission lines; Water: lakes, rivers, streams, swamps; Relief: slopes, depressions; Vegetation: trees cleared land, place names, water feature names, highway names.

The map created can serve both engineering and tourism purpose which makes the map a multipurpose map.

\section{Conclusions/Recommendations}

This system will provide students, academic and administrative staff and other exterior users the necessary information about the location of the campus facilities. The spatial and non-spatial information about campus is stored in ArcGIS geodatabase, this can be updated and used for administrative purposes. Due to the continuous growth of the university there is a need for continuous and regular update of the university facility map and its geodatabase to keep up with the infrastructural needs of the university.

The importance of the data obtained from this project cannot be overemphasized, because firstly, in order to tap the resources within the area, we must have an accurate knowledge of the area. This will help to make useful decisions. The study further emphasizes the importance of remote sensing and GIS in spatial analysis and planning. 


\section{References}

[1] Meyers J.R. (2000) GIS in the Utilities. https://www.geos.ed.ac.uk/ gisteac/gis_book_abridged/files/ch57.pdf

[2] Nwilo, P.C., Peter, O.V. and Badejo, O.T. (2000) Geoinformatics as a Tool for Facilities Management. Proceedings of Technical Session NIS AGM Edo, University of Lagos, Lagos.

[3] Stuart, R. and Kevin, H. (2010) Geographic Information Systems (GIS) for Facility Management. IFMA Foundation. http://www.ifmafoundation.org/

[4] Weiss, M.D. (2009) Ten Innovative Uses for GIS in Facility Management. Advanced-Infrastructure.

https://healthmap.wordpress.com/2009/05/15/ten-innovative-uses-for-gis-in-facilit y-management/

[5] Bassham, C.R. (1994) GIS/Municipal Management Information System at Texas A\&M University. Texas A\&M University.

[6] Haeberling, C. (2002) 3D Map Presentation-A Systematic Evaluation of Important Graphic Aspects. International Cartographic Association (ICA) Mountain Cartography Workshop “Mount Hood”, 15-19 May 2002, Timberline Lodge, Mt. Hood, Oregon.

[7] Bello, I.E. and Ikhuoria, I.A. (2015) 3D Cartographic Model And Animation of As-built Educational Landuse of UNIBEN, Nigeria. National Space Research and Development Agency (NASRDA), Abuja, Nigeria, University of Benin (UNIBEN), Benin City.

[8] Agbaje, G.I. and Omoyajowo, B. (2010) Generation of Geospatial Datasets for Facilities Management in Abuja, Nigeria. National Space Research and Development Agency, Abuja.

[9] Khalil, R. (2013) The Accuracy of GIS Tools for Transforming Assumed Total Station Surveys to Real World Coordinates. Journal of Geographic Information System, 5, 486-491. https://doi.org/10.4236/jgis.2013.55045

[10] Stanislawski, L., Finn, M.P., Usery, E.L. and Robinette, P.L. (2007) Development of a Blunder Detection Approach for Automated Point Matching During Vector to Image Data Integration. Proceedings of American Society for Photogrammetry and Remote Sensing Annual Conference, Tampa, FL, May 7-11 2007. 